\title{
The Design of Management Information System for Construction Project Cost
}

\author{
WU Caixuan ${ }^{1, a}$ \\ ${ }^{1}$ Chongqing water resources and electric engineering college, Chongqing Yangchuan 402160, \\ China \\ aWucaixuan@yeah.net
}

\begin{abstract}
Keywords: Management Information System, Construction Engineering, Project Cost
\end{abstract}
\begin{abstract}
With the continuous expansion of business, the scale of engineering construction project has developed rapidly, project type and more miscellaneous, the amount of data is becoming more and more big, so to design a computer management information system, using computer strong processing power and storage capacity, the various forms of the original is data collection and preservation, so that the manager timely, comprehensive and accurate to obtain all of the information you need. Cost information management system in this paper, divided into price information module, project database module, engineering cost index database module, enterprise quota library module, online query module, and these modules are discussed in detail the design and construction process. System development can greatly convenient cost management personnel, satisfy the business enterprise modernization, informatization, enable enterprises to achieve greater economic and social benefits.
\end{abstract}

\section{Introduction}

With the rapid development of computer technology, the computer has been used in all walks of life, which has had a profound impact on human society. Along with the rapid development of China's construction industry, greatly promoted the process of urban development, realize the construction project construction and project management informatization is becoming very important. Traditional artificial cost management pattern already cannot adapt to the internationalization of the needs of the development path, and the investment in the construction engineering and construction project management process, and project management of construction engineering project investment forecast is the fundamental basis. So at the same time, the project cost budget is the basic control according to the whole construction project cost budget, and the construction project cost budget of accuracy will directly affect the construction of the project investment funds and project implementation schedule [1]. As much as possible so it is necessary to establish perfect management system, using computer assume all kinds of management work.

This paper first introduces the research background of the construction cost of the engineering project management information system, research purposes, and discusses the construction cost of the engineering project management system development present situation at home and abroad, then expounds the relevant theories of construction project cost. This paper USES a modular design concept, cost management information system can be divided into price information module, project database module, engineering cost index database module, and enterprise quota library module, online query module, and these modules are discussed in detail the design and construction process. The development of this system can greatly convenient cost management personnel, satisfy the business enterprise modernization, informatization, and enable enterprises to achieve greater economic and social benefits.

\section{Business process analysis of the construction project cost information system}

With the rapid development of Internet, the Internet technology, the construction enterprise project cost management mode of informatization has become the inevitable development trend [2]. At 
present, the computer information technology and Internet technology both speed and performance to be able to meet the needs of the enterprise information construction, enterprise information management mode in enterprise development play a role in the process of growing, and began to present a rapid development momentum. Construction project cost information system of project cost management is the basic thought of, and will provide the information to the related personnel, in order to achieve information sharing. Construction project cost information system includes business leaders, template design, template for examination and approval of personnel, the project cost, project management, system management personnel, suppliers, and the demand for the system function [3-4]. System business process, the construction project cost information system business flow chart is shown in figure 2.

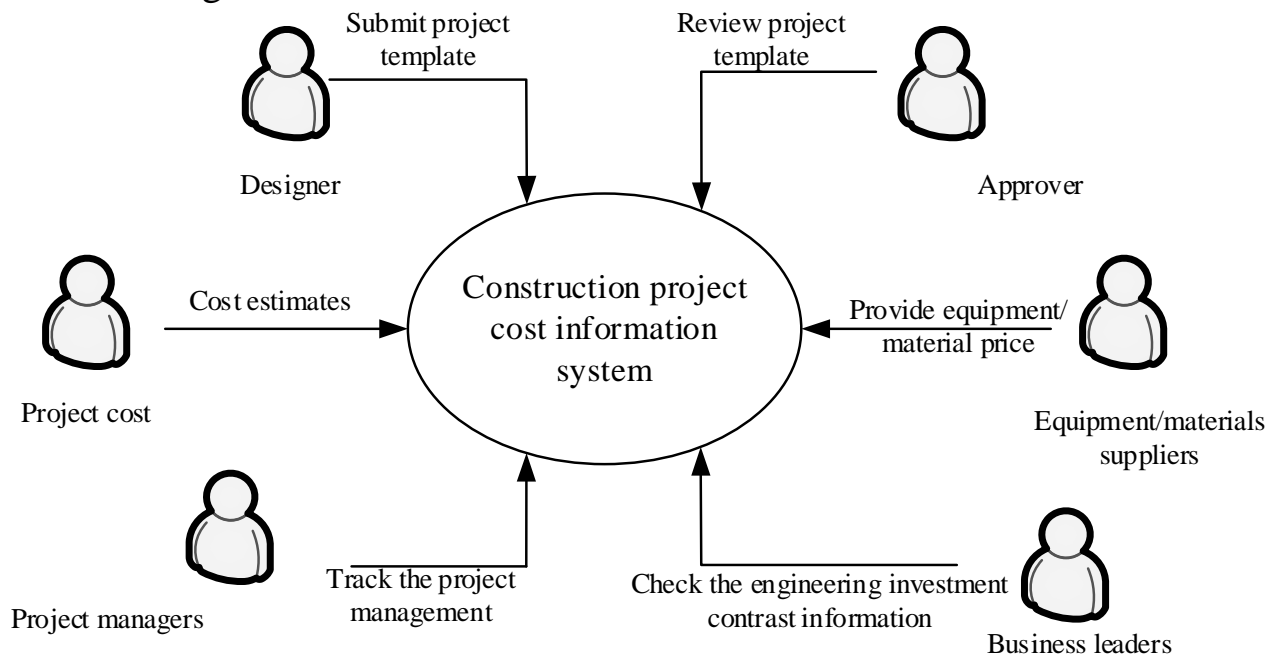

Figure 1. Business process of the construction project cost information system

Business leaders after the login system, can view the project information, project cost, project progress and project cost and error analysis was carried on. The template designer after login system, can create the template of engineering cost, the types and contents of the template to try to meet the needs of practical engineering, and engineering management. Template for examination and approval of personnel after the login system, may submit the examination and approval template design personnel cost template, will review by the template is put in the project cost information system database, will not return through the template to the template designer. And can view the project information. Engineering cost personnel after the login system, can choose the appropriate template, cost of the project cost estimation, can also manage the project, when a project is complete, you can view analysis estimated and actual cost. Engineering managers after the login system, can be to manage is the construction of the project, the price of the project cost information system database for maintenance, when a project is complete, you can view analysis estimated and actual cost. System management after the login system, and for all types of users in the system to add, delete. Can export data from the system, also can the data into the system. He can also make a backup of data in the system. The staff have the highest authority. Supplier after the login system, through the Internet real-time formulation and modification of the equipment material price, it'll be convenient for providers for material price.

\section{Functional requirements analysis for the construction project cost information system}

According to the demand analysis of construction project cost management system, construction engineering cost management system should include user management, cost management, project information management, materials equipment management, identifying markers for statistics and system auxiliary function [5], system function module chart is shown in figure 3. 


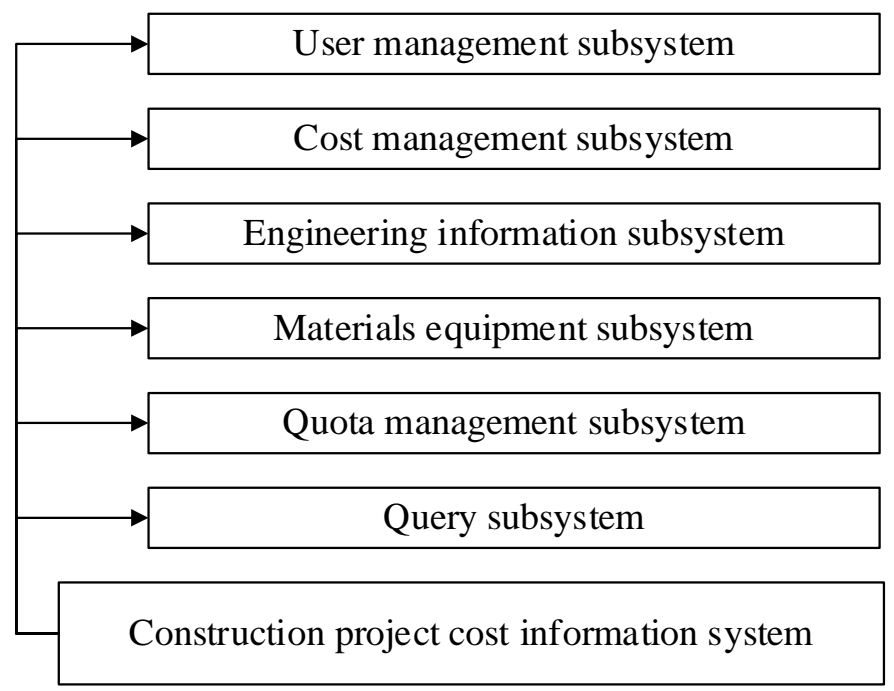

Figure 2. Functional module of the construction project cost information system

User management subsystem. User management subsystem is mainly used to participate in construction engineering project management of all personnel information, including adding new members (join), modify the user information, set the permissions for different users, when the user left after the project, to delete the user.

Cost management subsystem. Cost management subsystem mainly for engineering construction in the capital management, including the progress payment for examination and approval, construction progress statistics, project fund plan management, material plan approval, accounting settlement audit, cost analysis, etc.

Engineering information management subsystem. Engineering information management subsystem is mainly for engineering information management, including project to add, modify, delete, project classification, quantity statistics, etc.

Materials equipment management subsystem. Materials equipment management subsystem is mainly for engineering materials and equipment needed for management, including the writing of the procurement plan, bidding management, the purchase contract management, material storage registration and outflow.

Quota management subsystem. Quota management is mainly the management of construction projects in various costs, including artificial man-days click, materials, equipment, price, etc., mainly including to add quotas, modify, quotas, delete the quota and quota analysis, etc.

Query statistics subsystem. Identifying markers for statistics subsystem is mainly for the provision of staff related inquiry, statistics, different permissions users to your content and permissions + with Chad, query system, can generate the corresponding statements, and provide the print report function. The system has the function of auxiliary subsystem. System auxiliary function is mainly used for auxiliary system administrators for system maintenance and data backup, mainly including the initial parameter setting, data backup, system maintenance and user login.

\section{Overall design of the construction project cost management system}

Based on the above analysis, in the construction project cost management system, project department, cost department, finance department, purchasing department, design department, construction department is through the browser mode for the operations. Although these department independent of each other in the administration, but logically as a whole, for engineering construction services. They share data through the network, connect with each other, such as the cost of the department of materials directory, material budget price and construction contract, material plan is the purchasing department for material procurement and outbound basis, and outbound information of purchasing department and cost department for progress payment of beam and the basis of engineering settlement, one of purchasing department of materials information and outflow is the budget department on the basis of material price adjustment and so on. Construction 
engineering cost management system of various departments to communicate through the network, the overall system structure diagram as shown in figure 3.

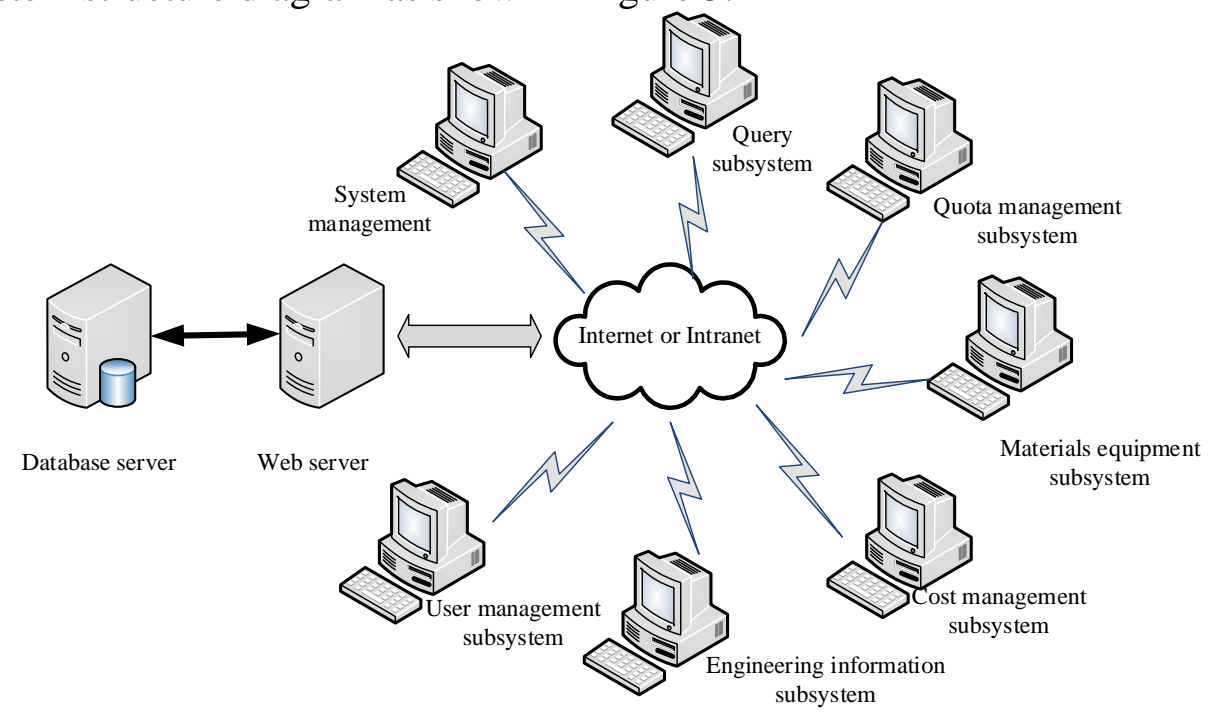

Figure 3. Hardware structure of the construction project cost management system

Construction engineering cost management system is development with the three-tier architecture, including the first layer is the client, the browser used to access data for each sector, the second layer is the middle layer is a Web server, the user deal with specific business logic, the third layer is the database server. The client through the browser sends a request to the Tomcat server when need to access the database, by unified interface components DAO to access the database. So the structure of the program structure is clear, than in pure JSP implementation procedure readability and reusability will be better.

\section{Conclusion}

Construction engineering cost management system is not only a management information system, but also reflects scientific and standardized management system and management system. In this paper, the construction project cost management system research, the use of the software engineering ideas and methods for system requirements analysis, focuses on the analysis of the main business processes, functional requirements analysis, on this basis, the construction project cost system carried on the detailed design, including architecture design, function module design and database design, program flow of logical structure design and physical design. The construction project cost management system designed by this paper can well solve the enterprise in the information they collect and organize the project cost related data problems, make full use of the completed project cost data to assist bidding project cost estimate and budget, to improve the competitiveness of the enterprises.

\section{References}

[1] P.E.D. Love, Z.A. Irani: Information \& Management, Vol. 40 (2003) No.7, p.649.

[2] S. Azhar: Leadership and Management in Engineering, Vol. 11 (2011) No.3, p.241.

[3] F. Ahlemann: International Journal of Project Management, Vol. 27 (2009) No.1, p.19.

[4] R. Sacks, L. Koskela, and B.A. Dave: Journal of construction engineering and management, Vol. 136 (2010) No.9, p.968.

[5] T. Hartmann, M. Fischer, and J. Haymaker: Advanced Engineering Informatics, Vol. 23 (2009) No.1 p.57. 